\title{
Effects of Insulin against Aluminium Induced Neurotoxicity in Wistar Rats
}

\author{
MD Amir Alam ${ }^{1}$, Garima Bansal ${ }^{2}$ \\ ${ }^{1}$ Department of Pharmacology, Saraswati Medical College, LIDA, Madhu Vihar, \\ P.O Asha Khera. NH 25, Lucknow Kanpur Highway, Unnao-209859, UP, India \\ ${ }^{2}$ Department of Pharmacology, Pacific Medical College and Hospital, Bhilon ka Bedla, \\ NH 27, Pratap Pura, Girwa, Udaipur-313001, Rajasthan, India
}

\begin{abstract}
Aluminium toxicity is well known to cause neurotoxicity leading to Alzheimer disease with dementia. The aim of the present study is to evaluate the effects of Insulin in Aluminium induced neurotoxicity. Thirty male wistar rats randomized into three groups (group V, D, T) of ten each were used for the study after obtaining institutional animal ethics committee approval. Chronic aluminium neurotoxicity was induced in the rats and the neurobehavior was evaluated using Morris water maze test, elevated plus maze test and rotarod test using standard methodologies. Group D rats exhibited significant deviation in performance of behavioural test of the study during day 1 (Morris water maze test- $18.6 \pm 9.5$, elevated plus maze test- $34.9 \pm 1.9$, rotarod test- $118.6 \pm 15.2$ ) and day 30 (Morris water maze test- $64.5 \pm 4.6$, elevated plus maze test- $72.1 \pm 3.9$, rotarod test- 110.7 \pm 9.3 ). Rats of group T showed attenuation in behavioural changes induced by aluminium toxicity ( $\mathrm{P}$ value: Morris water maze test-0.0002, elevated plus maze test- 0.0007 and rotarod test- 0.015 ). Insulin may play a role in neuroprotection against toxicity similar to that of aluminium induced neurotoxicity.
\end{abstract}

Keywords: Neurotoxicity, Aluminium, Insulin, Chronic, Neurobehaviour.

\section{Introduction}

Aluminium is a ubiquitous metal, which is potentially toxic to human. Aluminium (Al) accumulation has been implicated as a causative factor in a variety of disorders. Abnormally high amounts of the metal have been found in various neurological conditions; including dialysis encephalopathy, amyotrophic lateral sclerosis, Down syndrome, Parkinson's disease and Alzheimer's disease (AD). ${ }^{1,2}$

Aluminium can readily cross the blood brain barrier after systemic administration and may use the same high affinity receptor ligand system that has been postulated for iron. Once in the brain, $\mathrm{Al}$ accumulates in various regions including the hippocampus where it can interfere with synaptic plasticity in a dose dependent manner. Application of different Al salts has generated neurofibrillary degeneration similar to that found with patients of dementia, ${ }^{3}$ therefore Aluminium remains an environmental toxin that when accumulated in the brain in high amounts, can have devastating effects.

The full scale of mechanisms underlying Al neurotoxicity is likely to involve multiple pathways. It has been reported that Al may interfere with neuronal signaling through interactions with glutamate receptors or calcium channels and / or intracellular calcium homeostasis. ${ }^{4,5}$ Considerable

Corresponding author: Garima Bansal.Department of Pharmacology, Pacific Medical College and Hospital, Bhilon ka Bedla, NH 27, Pratap Pura, Girwa, Udaipur-313001, Rajasthan, India. Email: drgarimabansal@gmail.com Received: 17 April 2020. Revised: 16 June 2020. Published: 1 August 2020. 
evidence has been provided for an interaction of Al with the cholinergic system. ${ }^{6}$ The Al was described in relation with cholinergic transmission and signaling. The cholinergic system is also known to be particularly affected in $\mathrm{AD}$ and cholinergic signaling is crucially involved in learning and memory mechanisms. $^{7}$ Al can induce neuronal and glial cell death, ${ }^{8}$ extensive loss of synaptic contacts, and can at least potentiate the deposition of aggregated beta-amyloid protein in the brain parenchyma and within the cerebro-meningeal vasculature, ${ }^{9}$ which in turn can promote inflammatory events. $\mathrm{Al}$ can also interfere with axonal transport through binding of tau protein and other neurofilament peptides and the degeneration of neurofibrils in a tangle-like conformation. ${ }^{10}$ Advances in the understanding of both the bioinorganic chemistry of $\mathrm{Al}$ and the biochemistries of tau and amyloid precursor protein (APP) have strengthened the link between $\mathrm{Al}$ and neurofibrillary tangles (NFTs) and senile plaques (SPs) from one of association to one approaching an etiology. ${ }^{11}$

Aluminium has long been implicated in clinical conditions like senile and pre-senile dementia of Alzheimer's type. The AD is the most common form of dementia in the elderly and characterized histopathologically by extensive brain atrophy caused by neuron loss, ${ }^{12}$ intraneuronal accumulation of paired helical filaments (PHFs) composed of abnormal tau proteins-neurofibrillary tangles, ${ }^{13}$ and extracellular deposits of amyloid peptide $(A \beta)$ in neuritic plaques ${ }^{14}$ that are surrounded by a tract of neuroinflammation in specific regions of brain parenchyma including the cortex and hippocampus.

In addition to the neuropathologic lesions associated with $\mathrm{AD}$, significant deficits in neurochemical functions and indices have been observed. Treatment with cholinesterase inhibitor drugs is currently the standard of care. ${ }^{15}$ But the average durations of treatment and beneficial effects are not optimal in all cases, because of disappointing efficacy or poor tolerability of the initial treatment as well as secondary efficacy failure or adverse effects emerging during the maintenance phase. ${ }^{16}$ Moreover, no treatment has been shown to significantly delay the progression of the disease. Therefore, efforts to identify novel approaches in the management of patients with $\mathrm{AD}$ are required. Also, Insulin/ insulin like growth factors was related to the increased oxidative stress, reactive oxygen or nitrogen species, and neuroprotection; causing similar AD type dementia. ${ }^{17-19}$ The current study attempts to detect any improvement over presently available drugs using hither to less commonly tried therapies in AD. The aim of the present study is to evaluate the effects of Insulin in Aluminium induced neurotoxicity.

\section{Methods}

\section{Animals}

The present study was conducted in randomly selected adult Wistar rats of either sex (150-200gm, 6months). The animals were procured from the animal house of the institute. All the animals were housed in separate polypropylene cages (10 inch $\mathrm{x} 15$ inch) containing 2 rats each in the departmental animal room under standard laboratory conditions of ambient temperature of $25+2{ }^{\circ} \mathrm{C}$, with relative humidity of $65+5 \%$, and a 12-hour dark/light cycle. All the animals were allowed standard rodent pellet and tap water ad libitum. Each rat was used for experimentation only once. The experiments were performed between $10.00 \mathrm{~h}$ and $13.00 \mathrm{~h}$ to minimize circadian influences. The Institute Animal Ethical Committee (1204/ac/08/CPCSE) has approved the study design. 


\section{Drugs, Chemicals, and Animal Treatment}

Insulin was procured from Knoll Pharmaceuticals Ltd. Mumbai. Aluminium chloride was procured from Avantor Performance Materials India Ltd.

All the animals were acclimatized for one week following randomization and grouping. The animals were grouped in to three groups namely group V, D, T of ten animals each. The group V (normal control) rats received normal saline intraperitoneally for 30 days. The group D (disease control) rats received aluminium chloride intraperitoneally $(10 \mathrm{mg}$ $\mathrm{Al} / \mathrm{kg}$ body weight) for 30 days. The group $\mathrm{T}$ (treatment group) rats received aluminium chloride intraperitoneally (10mg Al / kg body weight) for 30 days along with insulin 0.2 $\mathrm{IU} / \mathrm{kg} / \mathrm{d}$, intraperitoneal during 16 th to 30 th day. Before giving insulin, the animals will be given dextrose $600 \mathrm{mg} / \mathrm{kg}$, i.p. to avoid hypoglycaemia.

Aluminium induced neurotoxicity: An experimental rat model of aluminium accumulation in the brain was developed to aid in determining neurotoxicity of aluminium (Al). Aluminium chloride will be dissolved in distilled water to prepare 35 a solution of concentration $10 \mathrm{mg} / \mathrm{mL}$. Al administered once daily by intraperitoneal injections of $\mathrm{AlCl3}$ (10mg Al / kg body weight) for 30 days. ${ }^{20}$

\section{Behavioural Parameters}

The behavioral tests were conducted during the five days (day 31-35) following the animal treatment. Morris water maze test was conducted on day 31-32, elevated plus maze test on day 33-34 and rotarod test on day 35.

\section{Morris Water Maze Test}

Morris water maze test was performed following previous method. Training in the maze was given for 5 days with one session of four trials each day to all rats in the study. The platform remained in the same place during all the training sessions. Training was followed immediately by test Session. The procedure during all subsequent test sessions was identical to the training. Escape latency, the time duration between the animal placed in water and escape to platform was recorded and evaluated. ${ }^{21}$

\section{Elevated plus Maze Test}

Elevated plus maze test was done as described in previous studies. ${ }^{22}$ The elevated plus-maze test was used to evaluate spatial, long term memory, following the procedure described. Each mouse was placed at the end of an open arm. Transfer latency, the time taken by the mouse to move in to one of the enclosed arms, was recorded on the 1 st day. An arm entry is defined as the entry of all the four feet of the animal into closed arm. If the animal did not enter an enclosed arm within 90s, it was gently pushed into one enclosed arm, and the Transfer latency was assigned as 90s. The mouse was allowed to explore the maze for 20 s and was then returned to its home cage.

\section{Rotarod Test}

The muscle strength and coordination is evaluated. Rats were placed on the metallic rod $(2 \mathrm{~cm})$ in diameter rotating at a rate of 20 revolutions per minute. Circular section divided the linear space of the rod in to 4 lengths so that 4 rats could be initially screened for their ability to maintain themselves on the rotating rod for more than 3 minutes. If the animal after treatment cannot remain on the rod for 3 successive trials of 3 minutes each, the test was considered positive i.e. motor inco-ordination was produced by the test compound. Rotarod performance was evaluated as fall-off time in seconds from the rotating $\mathrm{rod}(20 \mathrm{rpm} / \mathrm{min})$ with in a period of $3 \min ^{23}$ 
Statistical Analysis

All results data was represented as mean $\pm \mathrm{SD}$.

Difference between groups was calculated with one-way ANOVA followed by Post Hoc Scheffe's test. P value $\leq 0.05$ was considered to be statistically significant.

\section{Results and Discussion}

Aluminium chloride (10mg Al / kg body weight, intraperitoneal) for 30 days was reported to induce neurotoxicity with aberration in memory and learning.20 Hence this was taken for screening $0.2 \mathrm{IU} / \mathrm{kg} / \mathrm{d}$ insulin against this aluminium induced neurotoxicity.

Effect of Insulin on Morris water maze performance

The aluminium chloride treated group $\mathrm{D}$ rats showed increased escape latency on 30th day $(64.5 \pm 4.6)$ in comparison to normal control group $\mathrm{V}$ rats $(24.8 \pm 8.5)$ and the day one performance was comparable between group $\mathrm{D}$ and group $\mathrm{V}$ rats $(\mathrm{P}$ value $=0.54)$. Insulin treated group $\mathrm{T}$ rats $(55.1 \pm 4.54)$ showed decrease in latency time $(\mathrm{P}$ value $=0.0002)$ in comparison to the group $\mathrm{D}$ rats $(64.5 \pm 4.6)$ on 30th day of the study. (Figure 1)

In this animal experimental design, insulin was screened for neuroprotective effects against Al induced neurotoxicity using behavioural parameters. This includes battery of tests to evaluate neurobehavioral effects of $\mathrm{AlCl}_{3}$ administered intraperitoneal to the rats. The neurobehavioral toxicity has been screened by using a battery of neuropsychobehavioral tests evaluating all aspects of memory, like, spatial memory, conditioned response and working memory. The paradigms used in the study are Morris water maze, elevated plus maze, rotarod test. Spatial memory (a type of declarative memory) is evaluated by various models of which Morris water maze is considered to be the best model due to several advantages like food and water deprivation is not required in this test, water provides a uniform intra maze environment, thus eliminating any olfactory interference. In various experiments Morris water maze has been successfully used for evaluation of anti-dementia and anti-amnesic drugs. The conditioning processes have been considered

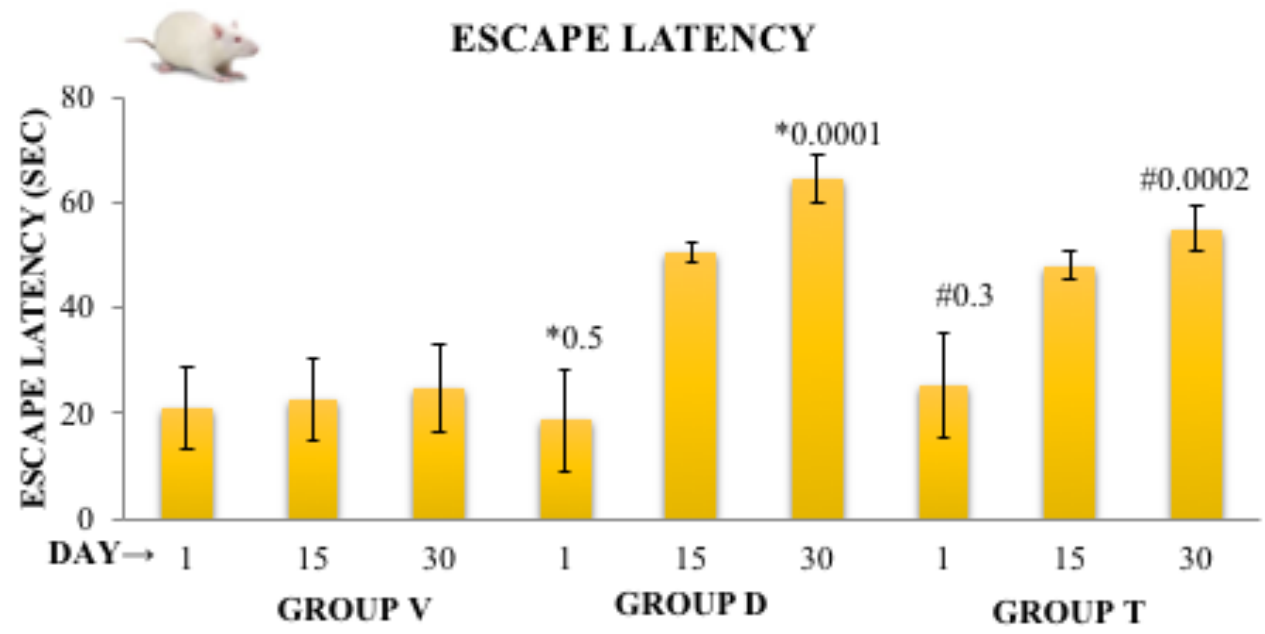

Figure 1. Escape latency of Morris water maze test. SEC- seconds, GROUP V- normal control group, GROUP D- disease induced group, GROUP Ttreatment group. *-P value for comparison between group $\mathrm{V}$ and group $\mathrm{D}$, \#- $P$ value for comparison between group $D$ and group $T$. 


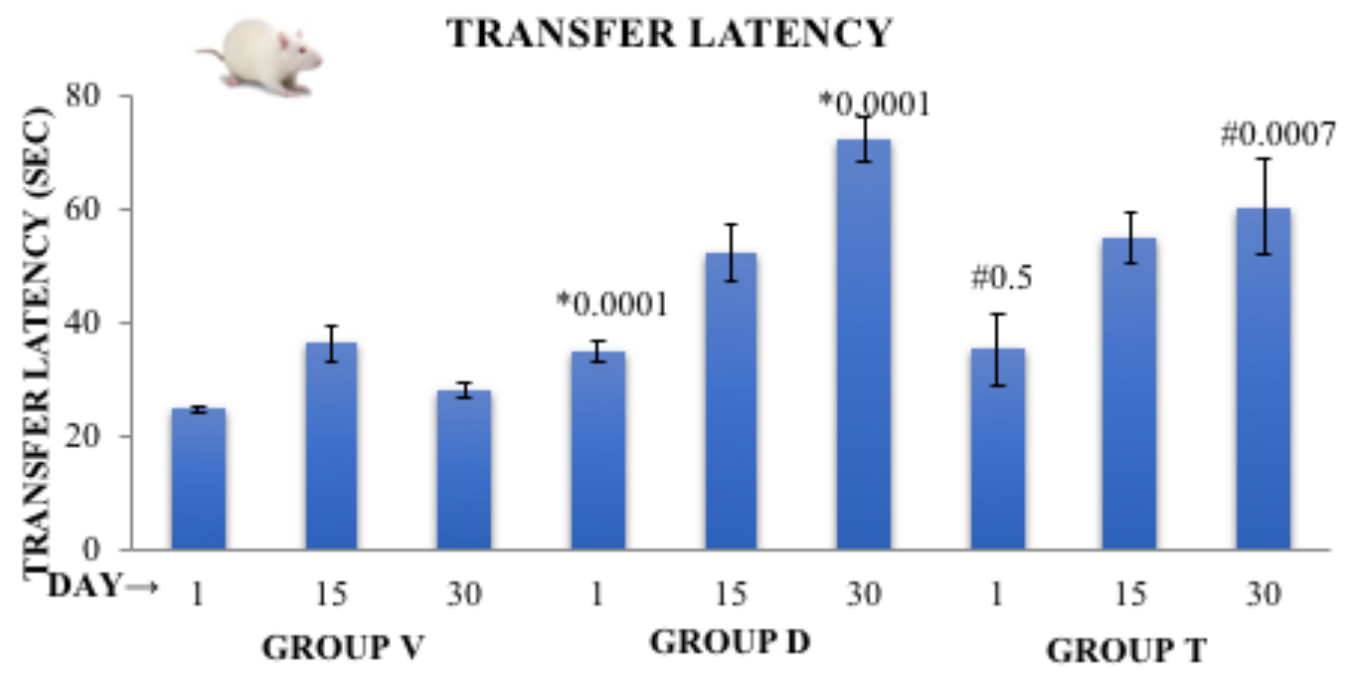

Figure 2. Transfer Latency of Elevated plus maze test. SEC- seconds, GROUP V- normal control group, GROUP D- disease induced group, GROUP Ttreatment group. *-P value for comparison between group $\mathrm{V}$ and group $\mathrm{D}$, \#- P value for comparison between group $D$ and group $T$

to be the basic element of learning. ${ }^{24}$ This test has been included to evaluate the effect of $\mathrm{Al}$ salt on learning and memory.

Effect of Insulin in Elevated Plus Maze Performance

The transfer latency increased in group $\mathrm{D}$ rats $(52.2 \pm 4.9,72.1 \pm 3.9)$ in comparison to group $\mathrm{V}$ (36.5 $\pm 3.2,28.2 \pm 1.4)$ on 15 th day and 30 th day $(\mathrm{P}$ value $=0.0001)$. The insulin treated group $\mathrm{T}$ rats $(60.4 \pm 8.26)$ showed significant decrease $(\mathrm{P}$ value $=0.0007)$ in transfer latency on day 30 in comparison to group D rats $(72.1 \pm 3.9)$. (Figure 2)

\section{Effect of Insulin on Motor Behaviour}

The latency of fall was significantly decreased in group D rats $(72.1 \pm 3.9)$ on 30 th day of performance in comparison to group $\mathrm{V}$ rats (28.2 \pm 1.4$)$. In comparison to group D rats, group $\mathrm{T}$ rats $(60.4 \pm 8.26)$ showed increase in latency of fall on 30th day $(\mathrm{P}$ value $=0.01)$. (Figure 3)

Aluminium chloride (10mgAl/ kg body weight, intraperitoneal) for 30 days was reported to induce neurotoxicity with aberration in memory and learning. 20 Hence this was taken for screening $0.2 \mathrm{IU} / \mathrm{kg} / \mathrm{d}$ insulin against this aluminium induced neurotoxicity.

Effect of Insulin on Morris water maze performance

The aluminium chloride treated group D rats showed increased escape latency on 30th day (64.5 \pm 4.6$)$ in comparison to normal control group $\mathrm{V}$ rats $(24.8 \pm 8.5)$ and the day one performance was comparable between group $\mathrm{D}$ and group $\mathrm{V}$ rats $(\mathrm{P}$ value $=0.54)$. Insulin treated group $\mathrm{T}$ rats $(55.1 \pm 4.54)$ showed decrease in latency time $(\mathrm{P}$ value $=0.0002)$ in comparison to the group D rats $(64.5 \pm 4.6)$ on 30 th day of the study. (Figure 1)

In this animal experimental design, insulin was screened for neuroprotective effects against Al induced neurotoxicity using behavioural parameters. This includes battery of tests to evaluate neurobehavioral effects of $\mathrm{AlCl}_{3}$ administered intraperitoneal to the rats. The 


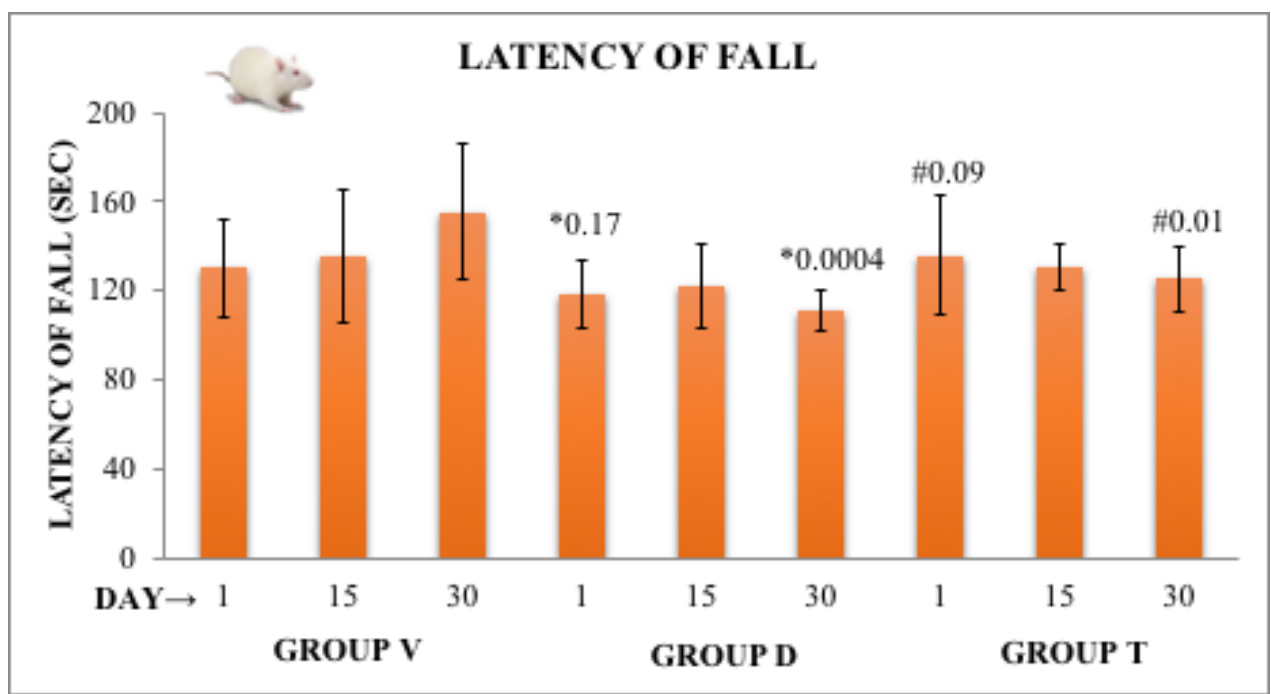

Figure 3. Latency of fall of Rotarod test. SEC- seconds, GROUP V-normal control group, GROUP D- disease induced group, GROUP T- treatment group. *-P value for comparison between group $V$ and group $D$, \#- $P$ value for comparison between group $\mathrm{D}$ and group $\mathrm{T}$.

neurobehavioral toxicity has been screened by using a battery of neuropsychobehavioral tests evaluating all aspects of memory, like, spatial memory, conditioned response and working memory. The paradigms used in the study are Morris water maze, elevated plus maze, rotarod test. Spatial memory (a type of declarative memory) is evaluated by various models of which Morris water maze is considered to be the best model due to several advantages like food and water deprivation is not required in this test, water provides a uniform intra maze environment, thus eliminating any olfactory interference. In various experiments Morris water maze has been successfully used for evaluation of anti-dementia and anti-amnesic drugs. The conditioning processes have been considered to be the basic element of learning. ${ }^{24}$ This test has been included to evaluate the effect of $\mathrm{Al}$ salt on learning and memory.

Effect of Insulin in Elevated Plus Maze Performance

The transfer latency increased in group D rats $(52.2 \pm 4.9,72.1 \pm 3.9)$ in comparison to group $\mathrm{V}$
$(36.5 \pm 3.2,28.2 \pm 1.4)$ on 15 th day and 30th day $(\mathrm{P}$ value $=0.0001)$. The insulin treated group $\mathrm{T}$ rats $(60.4 \pm 8.26)$ showed significant decrease $(\mathrm{P}$ value $=0.0007)$ in transfer latency on day 30 in comparison to group D rats $(72.1 \pm 3.9)$. (Figure 2)

\section{Effect of Insulin on Motor Behaviour}

The latency of fall was significantly decreased in group D rats $(72.1 \pm 3.9)$ on 30th day of performance in comparison to group $\mathrm{V}$ rats (28.2 \pm 1.4$)$. In comparison to group D rats, group $\mathrm{T}$ rats $(60.4 \pm 8.26)$ showed increase in latency of fall on 30th day (P value $=0.01)$. (Figure 3)

In this study, Aluminium chloride intraperitoneal administration (10mg $\mathrm{Al} / \mathrm{kg}$ body weight) between 1st day of experiment and 30th day showed significant decrease in performance of behavioural activity including Morris water maze activity (18.6 \pm 9.5 to $64.5 \pm 4.6$ seconds), elevated plus maze behaviour ( $34.9 \pm 1.9$ to $72.1 \pm 3.9$ seconds) and rotarod behaviour $(118.6 \pm 15.2$ to $110.7 \pm 9.3)$. 
This neurobehavioural toxicity was attenuated by insulin administration $(0.2 \mathrm{IU} / \mathrm{kg} / \mathrm{d}$, i.p) exhibited in all the three behavioural tests $(\mathrm{P}$ value $=0.0002 ; 0.0007 ; 0.01)$. Overall motor behavior was not much affected in all the group rats.

Behavior can be defined as the end product of a variety of sensory, motor and integrative processes occurring in the nervous system. ${ }^{25}$ The functional capacity of the central nervous system cannot be determined by histological or even physiological studies without behavioral analysis. ${ }^{26}$ Neurobehavioral methods are being used with increasing frequency intoxicity studies to assess the deleterious effects of chemicals and physical factors on presumption that they are more sensitive than other tests in determining toxicity due to the fact that behavior is a functional indicator of the net sensory, motor and integrative processes occurring in the central and peripheral nervous system. Aluminium chloride affect the nervous system and produce effects which are manifested in the form of variety of symptoms and no single test can evaluate its neurobehavioral toxicity.

Various studies have been done evaluating the Aluminium induced neurobehavioral effects and morphological changes in the rat brain. ${ }^{27,28}$ Animals loaded with aluminium develop both symptoms and brain lesions that are similar to those found in AD. The performance of the control group animals (Al treatment for 30days) at all the three-neurobehavioral paradigms was significantly lower than the vehicle group (normal saline treatment for 30days). The decline in cognitive function was assessed at 15 days and 30days of treatment. There was a constant decline in memory of $\mathrm{Al}$ treated animals.

Studies have confirmed that glucose administration can facilitate memory in healthy humans and in patients with Alzheimer's disease. Interestingly, glucose effects on memory appear to be modulated by insulin sensitivity (efficiency of insulin-mediated glucose disposal). ${ }^{29}$ Biological data suggests that insulin may contribute to normal cognitive functioning and that insulin abnormalities may exacerbate cognitive impairments. In animals, systemic insulin administration has been associated with memory deficits, likely due, in part to hypoglycaemia that occurs when exogenous insulin is not supplemented with glucose to maintain euglycemia. Therefore, in this study insulin administration was preceded by fructose administration by half an hour to prevent peripheral hypoglycaemia. In the present investigation, the dose of insulin with fructose improved memory significantly even though the values are somewhat better than control.

Results of a recent study indicate a direct action of prolonged (8weeks) intranasal administration of insulin on brain functions, improving declarative memory and mood in the absence of systemic side effects. ${ }^{30}$ Many studies are available which have evaluated the effect of insulin on the neuropathological mechanisms of memory deterioration, ${ }^{31}$ but a few studies are there which have evaluated the effect of insulin treatment on retrieval of memory for a long duration of time. Studies, which have shown a positive effect of insulin administration on learning and retrieval, are short duration studies. Epidemiological evidence suggests that insulin resistance influences the risk of developing AD. ${ }^{32,33}$

The increasing evidence of insulin resistance in $\mathrm{AD}$ and other numerous mechanisms through which insulin may affect clinical and pathological aspects of the disease suggests that improving insulin effectiveness may have therapeutic benefits for patients of AD. ${ }^{34}$ 
The present work has shown that exogenous insulin helps in attenuation of aluminium chloride induced neurotoxicity. Chen $\mathrm{Y}$ et al., (2014) have only shown indirect evidence for role of insulin like growth factors in pathophysiology of Alzheimer Disease.35 Similarly Iwamoto T et al., (2014) have not shown any effect on whole animal model of memory loss, nor have they tested it on aluminium chloride induced. Their work only points to emerging evidence of insulin-like growth factor 2 as a memory enhancer. ${ }^{36}$

\section{Limitations}

This study would have been even screened in diabetic rat models which would give more information related to diabetes association with neurotoxicity and neuroprotective role of insulin. Because of practical limitations, biochemical and histological studies were not possible to perform in this study. Only single dose has been evaluated in this study, further studies may be required to explore the activity of larger doses.

\section{Conclusion}

The present study revealed the role of insulin in neuroprotection against chronic exposed aluminium induced neurotoxicity. This may be further explored in other models and provide substantial evidence to aid the susceptible diabetic population.

\section{Acknowledgement}

Nil

\section{Funding}

None

\section{Conflict of Interest}

None declared

\section{References}

1. Zatta PF. Biological models for the study of aluminium neurotoxicity. ACTA MEDICA
ROMANA. 1997;35:592-600.

2. Ghanta M, Panchanathan E, Lakkakula BV, Narayanaswamy A. Retrospection on the role of soluble guanylate cyclase in parkinson's disease. Journal of pharmacology \& pharmacotherapeutics. 2017;8(3):87.

3. Klatzo I, WISNIEWSKI H, Streicher E. Experimental production of neurofibrillary degeneration: 1. Light microscopic observations. Journal of neuropathology and experimental neurology. 1965;24(2):187-99.

4. Platt B, Haas H, Büsselberg D. Aluminium reduces glutamate-activated currents of rat hippocampal neurones. Neuroreport. 1994;5(17):2329-32.

5. Ghanta M, Panchanathan E, Lakkakula BV, Narayanaswamy A, Abhinand PA, Antony S. Molecular docking analysis of phytoconstituent from Momordica charantia with Guanylate Cyclase catalytic domain. Bioinformation. 2018;14(7):378.

6. Meiri H, Banin E, Roll M, Rousseau A. Toxic effects of aluminium on nerve cells and synaptic transmission. Progress in neurobiology. 1993;40(1):89-121.

7. Cain DP. Testing the NMDA, long-term potentiation, and cholinergic hypotheses of spatial learning. Neuroscience \& Biobehavioral Reviews. 1998;22(2):18193.

8. Suárez-Fernández MB, Soldado $A B$, Sanz-Medel A, Vega JA, Novelli A, Fernández-Sánchez MT. Aluminuminduced degeneration of astrocytes occurs via apoptosis and results in neuronal death. Brain research. 1999;835(2):125-36.

9. Bondy SC, Truong A. Potentiation of beta-folding of $\beta$-amyloid peptide 25-35 by aluminum salts. Neuroscience letters. 1999;267(1):25-8.

10. Troncoso JC, Sternberger NH, Sternberger LA, Hoffman PN, Price DL. Immunocytochemical studies 
of neurofilament antigens in the neurofibrillary pathology induced by aluminum. Brain research. 1986;364(2):295-300.

11. Drewes G, Ebneth A, Mandelkow EM. MAPs, MARKs and microtubule dynamics. Trends in biochemical sciences. 1998;23(8):307-11.

12. Whitehouse PJ, Price DL, Struble RG, Clark AW, Coyle JT, Delon MR. Alzheimer's disease and senile dementia: loss of neurons in the basal forebrain. Science. 1982;215(4537):1237-9.

13. Holzer M, Holzapfel HP, Zedlick D, Brückner MK, Arendt T. Abnormally phosphorylated tau protein in Alzheimer's disease: heterogeneity of individual regional distribution and relationship to clinical severity. Neuroscience. 1994;63(2):499-516.

14. Hsiao K, Chapman P, Nilsen S, Eckman C, Harigaya Y, Younkin S et al. Correlative memory deficits, $\mathrm{A} \beta$ elevation, and amyloid plaques in transgenic mice. Science. 1996;274(5284):99-103.

15. Grutzendler J, Morris JC. Cholinesterase inhibitors for Alzheimer's disease. Drugs. 2001;61(1):41-52.

16. Emre M. Switching cholinesterase inhibitors in patients with Alzheimer's disease. International journal of clinical practice. Supplement. 2002;127:64-72.

17. Bedse Gaurav, Di Domenico Fabio, Serviddio Gaetano, Cassano Tommaso. Aberrant insulin signaling in Alzheimer's disease: current knowledge. Frontiers in Neuroscience. 2015;9:204.

18. Stockhorst U, de Fries D, Steingrueber HJ, Scherbaum WA. Insulin and the CNS: effects on food intake, memory, and endocrine parameters and the role of intranasal insulin administration in humans. Physiology \& behavior. 2004;83(1):47-54.

19. van Dam PS, Aleman A. Insulin-like growth factor-I, cognition and brain aging. European journal of pharmacology. 2004;490(1-3):87-95.

20. Ogasawara Y, Sakamoto T, Ishii K, Takahashi H, Tanabe S. Effects of the administration routes and chemical forms of aluminum on aluminum accumulation in rat brain. Biological trace element research. 2002;86(3):269-78.

21. Morris R. Developments of a water-maze procedure for studying spatial learning in the rat. Journal of neuroscience methods. 1984;11(1):47-60.

22. Pellow S, Chopin P, File SE, Briley M. Validation of open: closed arm entries in an elevated plus-maze as a measure of anxiety in the rat. Journal of neuroscience methods. 1985;14(3):149-67.

23. Dunham NW, Miya TS. A note on a simple apparatus for detecting neurological deficit in rats and mice. Journal of the American Pharmaceutical Association. 1957;46(3):208-9.

24. Valzelli L, Essman WB. Psychopharmacology: An introduction to experimental and clinical principles. Spectrum Publications.; 1973.

25. Tilson HA. Harry GJ. Behavioral principles for use in behavioural toxicology and pharmacology. In: Nervous system toxicology. Editor. C. Mitchell. Raven Press. NewYork. 1982:1-27.

26. Mello NK. Behavioral toxicology: a developing discipline. In Behavioral Pharmacology. Boston: Springer; 1975.

27. Platt B, Fiddler G, Riedel G, Henderson Z. Aluminium toxicity in the rat brain: histochemical and immunocytochemical evidence. Brain research bulletin. 2001;55(2):257-67.

28. Roloff EV, Platt B, Riedel G. Longterm study of chronic oral aluminum exposure and spatial working memory in rats. Behavioral neuroscience. 2002;116(2):351. 
29. Watson GS, Craft S. Modulation of memory by insulin and glucose: neuropsychological observations in Alzheimer's disease. European journal of pharmacology. 2004;490(1-3):97-113.

30. Benedict C, Hallschmid M, Hatke A, Schultes B, Fehm HL, Born $\mathrm{J}$ et al. Intranasal insulin improves memory in humans. Psychoneuroendocrinology. 2004;29(10):1326-34.

31. Carro E, Torres-Aleman I. The role of insulin and insulin-like growth factor I in the molecular and cellular mechanisms underlying the pathology of Alzheimer's disease. European journal of pharmacology. 2004;490(1-3):127-33.

32. Leibson CL, Rocca WA, Hanson VA, Cha R, Kokmen E, O'brien PC et al. Risk of dementia among persons with diabetes mellitus: a population-based cohort study. American journal of epidemiology. 1997;145(4):301-8.

33. Ott A, Stolk RP, Hofman A, van Harskamp F, Grobbee DE, Breteler MM. Association of diabetes mellitus and dementia: the Rotterdam Study. Diabetologia. 1996;39(11):1392-7.

34. Malhotra S, Kondal A, Shafiq N, Sidhu S, Bhasin DK, Pandhi P. A comparison of observational studies and controlled trials of heparin in ulcerative colitis. International journal of clinical pharmacology and therapeutics. 2004;42(12):690-4.

35. Chen Y, Deng Y, Zhang B, Gong CX. Deregulation of brain insulin signaling in Alzheimer's disease. Neuroscience bulletin. 2014;30(2):282-94.

36. Iwamoto T, Ouchi Y. Emerging evidence of insulin-like growth factor 2 as a memory enhancer: a unique animal model of cognitive dysfunction with impaired adult neurogenesis. Reviews in the Neurosciences. 2014;25(4):559-74. 